\title{
Electrodeposited AuNPs/rGO Nanocomposite as sensor for Cr(VI) Determination in Water
}

\author{
Ye Liu ${ }^{1}$, Guowei Gao ${ }^{1,2}$, Jingfang $\mathrm{Hu}^{2, *}$, Xiaoping $\mathrm{Zou}^{2}$, \\ ${ }^{1}$ Detectation Technology \& Automation Equipment, Beijing Information Science \& Technology \\ University, Beijing 100192,China \\ ${ }^{2}$ Key Laboratory of sensor, Beijing Information Science \& Technology University, Beijing 100101, \\ China \\ *E-mail: jfhu@ bistu.edu.cn
}

doi: $10.20964 / 2018.12 .05$

Received: 8 May 2018 / Accepted: 30 August 2018 / Published: 5 November 2018

\begin{abstract}
A facile two-step electrochemical deposition of gold nanoparticles (AuNPs)/reduced graphene oxide (rGO) (AuNPs/rGO) nanocomposite was developed for $\mathrm{Cr}(\mathrm{VI})$ determination in water. First, electrodeposition of rGO on GCE by electroreduction of GO using cyclic voltammetry (CV), and then AuNPs were electrodeposited on $\mathrm{rGO}$ sheets using $\mathrm{CV}$ to obtain as AuNPs/rGO/GCE. The AuNPs/rGO nanocomposite was characterized by scanning electron microscopy (SEM), transmission electron microscopy (TEM) and energy dispersive X-Ray spectroscopy (EDS) analysis. The deposition time, and concentration of $\mathrm{HCl}$ supporting electrolyte were respectively optimized for $\mathrm{Cr}(\mathrm{VI})$ determination. Square wave voltammetry (SWV) was applied for the detection of $\mathrm{Cr}(\mathrm{VI})$. The experimental results demonstrated the AuNPs/rGO/GCE has excellent electrocatalytic ability for $\mathrm{Cr}(\mathrm{VI})$ reduction, and a linear range of $0.1 \mu \mathrm{M}-30 \mu \mathrm{M}$, with a high sensitivity of $0.79915 \mu \mathrm{A} / \mu \mathrm{molL}^{-1}$, and a detection limit of $0.046 \mu \mathrm{M}(\mathrm{S} / \mathrm{N}=3$ ) for $\mathrm{Cr}(\mathrm{VI})$ determination. The signal remained $92.98 \%$ after $12 \mathrm{~h}$ measurement suggested that the AuNPs/rGO nanocomposite has good stability for $\mathrm{Cr}(\mathrm{VI})$ determination. The common interfering irons of $\mathrm{Mg}^{2+}, \mathrm{Zn}^{2+}, \mathrm{Cu}^{2+}, \mathrm{Mn}^{2+}$ and $\mathrm{Cr}^{3+}$ were separately investigated, and less than $2 \%$ deviation values were obtained, indicating that the proposed AuNPs/rGO nanocomposite has good selectivity for $\mathrm{Cr}(\mathrm{VI})$ determination.
\end{abstract}

Keywords: $\mathrm{Cr}(\mathrm{VI})$ determination; AuNPs/rGO nanocomposite; electrochemical deposition; square wave voltammetry

\section{$\underline{\text { FULL TEXT }}$}

(C) 2018 The Authors. Published by ESG (www.electrochemsci.org). This article is an open access article distributed under the terms and conditions of the Creative Commons Attribution license (http://creativecommons.org/licenses/by/4.0/). 